\title{
Proclo, Dionisio y el pensamiento eriugeniano en la Expositio de Bertoldo de Moosburg
}

\author{
Ezequiel Ludueña \\ Universidad de Buenos Aires, Argentina
}

Recibido el 10/12/2019/Aceptado el 23/02/2020

\begin{abstract}
Resumen
Uno de los objetivos de la Expositio in Elementationem theologicam de Bertoldo de Moosburg es señalar un acuerdo substancial entre el pensamiento de Proclo y el del discípulo de Pablo, "Dionisio Areopagita". En este sentido, es importante el empleo que hace Bertoldo de un distingo agustiniano: aquel entre el orden de la providencia voluntaria y el orden de la providencia natural. Para Bertoldo, estas no se oponen; al contrario, están, en lo esencial, de acuerdo. Un ejemplo de esta armonía está dado precisamente por la coincidencia fundamental que Bertoldo cree advertir entre Proclo -cuya Elementatio representa el punto de vista del orden de la providencia natural-y Dionisio - que, en general, ofrece el punto de vista del orden de la providencia voluntaria. Construir un diálogo entre ambos pensadores es uno de los principales objetivos de Bertoldo. Ahora bien, en ese proyecto, al pensamiento eriugeniano le está reservado un papel preciso, en particular en lo concerniente a la comprensión de la metafísica politeísta de Proclo. Resulta revelador atender a la forma en que Bertoldo introduce las citas de sus varias fuentes eriugenianas. Parece claro que, en la Expositio, el eriugeniano es entendido como un pensamiento cristiano de orden filosófico que media entre Proclo y Dionisio, entre un platonismo pagano y un platonismo cristiano.
\end{abstract}

\section{Proclus, Dionysius, and Eriugenian Thought in the Expositio of Berthold of Moosburg}

\begin{abstract}
One of the main purposes of the Expositio in Elementationem theologicam written by Berthold of Moosburg is to show that there is a substantial agreement between Proclus' thought and that of Paul's disciple, "Dionysius the Areopagite". Strongly linked to this view, is the use Berthold does of a fundamental Augustinian distinction, namely the distinction between the ordo providentiae naturalis and the ordo providentiae voluntariae. Berthold understands that these do not oppose each other; in fact, essentially, they agree. The relation between the thought of Proclus and that of Dionysius can be understood on the base of that distinction. In his Elementatio theologica, Proclus writes
\end{abstract}

Palabras clave

Proclo

Dionisio

Bertoldo de Moosburg

Eriúgena

Providencia
Keywords

Proclus Dionysius Berthold of Moosburg Eriugena Providence 
from the point of view of the ordo providentiae naturalis, whereas Dionysius (generally) writes from the point of view of the ordo providentiae voluntariae. That is the reason why a dialogue can be built between Proclus and Dionysius. In order to do this, regarding Proclus' metaphysical polytheism, Berthold employs as a mediator the Eriugenian teaching about the causae primordiales. This can be proved by paying attention to the way Berthold introduces his Eriugenian quotes, always as a Christian consideration of things according to the ordo providentiae naturalis, which, at the same time, is to be read as a Christian and philosophical interpretation of Dionysius' thought.

En un trabajo de 1989, Alain de Libera se refiere a la forma en que Alberto Magno, Ulrico de Estrasburgo, Teodorico de Freiberg y Bertoldo de Moosburg concibieron la relación entre la filosofía pagana y la doctrina cristiana.

Alberto Magno distingue entre la theologia o scientia divina y la theologia en el sentido aristotélico de filosofía primera; teología revelada y teología en el sentido de Aristóteles. Estas "teologías" difieren por su objeto de estudio. Los objetos de la primera son: el Deus triunus, Cristo y la Iglesia y las creaturas en cuanto medios para alcanzar la salvación. Los de la segunda, Dios como causa primera, las inteligencias y los motores de las esferas de las cosmologías greco-árabes, el ente y sus determinaciones (acto, potencia, etc.) y la doxografía. Además de estas diferencias explícitas, las dos "teologías" no comparten la misma concepción de lo divino. En realidad, la theologia de los filósofos -apunta de Libera- es una theiologia, un estudio de las substancias divinas -categoría aplicable no sólo a la causa primera sino también a las inteligencias y motores celestes (cfr. de Libera, 1989, 51-53). Por su parte, Ulrico de Estrasburgo retoma esta formulación y habla de theologia o sapientia divina, en el primer caso, y de sapientia philosophica o metaphysica, en el segundo (cfr. ibidem, 54-55). Tanto en Alberto como en Ulrico, el primer tipo de teología, la del Dios unitrino, es la teología de los Padres, la sapientia nostra.

Teodorico, por su parte, según de Libera, hizo residir la diferencia entre ambas teologías no en su objeto de estudio -ambas tratan de tota universitate entium- sino en una diversidad de puntos de vista. Pero igual que Alberto y Ulrico, Teodorico entiende por sapientia nostra la teología de los Padres, que se ocupa del llamado orden de la providencia voluntaria (ibidem, 57).

Esa expresión, "orden de la providencia voluntaria", responde a un distingo agustiniano. En el De Genesi ad litteram (VIII, 9, 17) se habla de un orden de la providencia voluntaria y de un orden de la providencia natural. El primero es el tema de estudio de lo que hoy en día denominamos "teología" -incluye el estudio de los ángeles, de los demonios, de las almas de los beatos, etc. El orden de la providencia natural corresponde al ámbito de los hechos producidos y regulados por las leyes de la naturaleza, e.g. si planto una semilla tarda necesariamente una determinada cantidad de tiempo en llegar a ser un árbol. Este último, para Teodorico, es el orden del que hablan los filósofos no cristianos, la "teología" de la que habla Aristóteles. Y antes que en Teodorico encontramos un esquema similar en Ulrico de Estrasburgo.

En su extensa Expositio sobre la Elementatio theologica de Proclo Bertoldo de Moosburg habría recuperado el tema pero habría ido más allá, al denominar sapientia nostra tanto al estudio del orden de la providencia voluntaria (la theologia de los Padres) como al del orden de la providencia natural (la theologia de los filósofos) siempre que tal estudio se haga en uno y otro caso a partir de lo que él considera que son las premisas del pensamiento platónico. Así, lo que -para Bertoldo- cae fuera del adjetivo nostra es la filosofía que se reduce al ámbito del ser en cuanto ser (cfr. ibidem, 60-64), es decir, la filosofía de los peripatéticos. 
Pero además, el dominico de Moosburg ya no habla de sapientia nostra, sino de supersapientia nostra. ${ }^{1}$ Así, advierte, entres los cristianos, el representante por excelencia del pensamiento platónico es Dionisio, a quien Bertoldo llama: Dionysius platonicus (40C, III: 42, 214) $)^{2}$. Mientras que entre los paganos el platónico por excelencia es Proclo.

Según Bertoldo, Dionisio dio su más clara expresión al pensamiento platónico acerca del orden de la providencia voluntaria: “...Dionisio habla como teólogo, sólo considera la procesión de las cosas a partir de Dios según el orden de la providencia voluntaria..." (5B, I: 116, 104-103). Esto no significa que no hallemos en Dionisio ideas esenciales acerca del orden de la providencia natural. ${ }^{3}$ Por ejemplo: Bertoldo encuentra en Dionisio la misma distinción entre tres tipos de unidad (secundum causam, secundum essentiam, secundum participationem) que Proclo expone en la primera cuestión sobre la providencia (cfr. 2E, I: 88, 237-247; y Ludueña, 2013a: 122-125). Pero, en general, en la Expositio, Dionisio representa el punto de vista del orden de la teología voluntaria. Y esa distinción es la base misma del esquema metafísico de toda la Expositio. En cuanto a Proclo, para Bertoldo, "es uno de esos «filósofos teólogos o teólogos filósofos» cuyo platonismo los acerca por así decir estructuralmente a la teología cristiana bien entendida: la teología-"platónica»- de Dionisio" (cfr. de Libera, 1994, 324). De todos los platónicos, Proclo fue quien, según el dominico, supo ordenar y explicar mejor que nadie los teoremas formulados por el mismo Platón. ${ }^{4}$ Por esto, la teología expuesta por Proclo en su Elementatio theologica representa el más perfecto grado de desarrollo de la reflexión platónica acerca del orden de la providencia natural. Así, hablando de la Elementatio, Bertoldo escribe: “...todo este libro trata sobre la totalidad de las cosas divinas... según el orden de la providencia natural, y no ya propiamente voluntaria" (Exp. Tit. I, I: 46, 319-323). Ahora bien, así como a veces se recurre a Dionisio para explicar el orden de la providencia natural, también podemos hallar referencias al orden de la providencia voluntaria ancladas en textos de Proclo -no en pasajes de la Elementatio, sino, por ejemplo, del De malorum existentia. ${ }^{5}$

Sin embargo, a la hora de ofrecer precisiones acerca de los dioses de Proclo en la Elementatio, Bertoldo no recurre a Dionisio, sino sobre todo a textos de raigambre eriugeniana, como se verá.

Una buena forma de acercarse a la distinción entre estos dos puntos de vista en el comentario de bertoldino a la proposición 10 de la Elementatio theologica: omne antarkes $(\text { sic })^{6}$ simpliciter bono deterius est. Bertoldo distingue allí entre dos órdenes divinos, emanados ambos de Dios: la antarkia y la hierarchia.

El término antarkia equivale a per se principatus (10A, I: 177, 11-12) y significa "el dominio o dominación mismos del príncipe o principio" (10A, I: 177, 13). Pero, según cómo lo consideremos, princeps puede hacer referencia a dos cosas (10A, I: 177, 15-16).

Puede significar (1) el princeps absoluto del universo (10A, I: 177, 17); in-originado, independens et liberum (10A, I: 177, 18). Desde su superplenitud, se extiende copiosamente a todos sus sujetos. En este sentido, el princeps gobierna todo su principado, le da principio, lo ordena y lo sustenta (10A, I: 177, 19-21); pero no forma parte de lo "gobernado", de otra manera, no podría gobernarlo en su totalidad (10A, I: 177, 21-22). O sea: está fuera de lo principiado, separatus y exemptus (10A, I: 177, 23-24). En este sentido, el Dios supremo (y sólo él) es simpliciteromnium princeps, gobernante del único principado total que es el universo.

Pero dentro del único principado total, hay plures partiales principatus (10A, I: 177, 24); regidos por diversos príncipes parciales (10A, I: 177, 25-27). Son llamados "príncipes" por el lugar que ocupan dentro del principado total: "en cuanto partes del
1. Así se llama la excelente disertación doctoral, aún inédita, de Evan A. King: Supersapientia: A Study of Berthold von Moosburg, Cambridge, 2016.

2. Las referencias a la Expositio se harán de aquí en más indicando: número de preposición, sección, vol. de la edición crítica (consignada en la bibliografía), página, línea.

3. De hecho, el texto recién citado comienza así: Sed dices, Dionysius loquitur ut theologus..., fórmula que parece dar a entender que no es Bertoldo quien habla sino alguien que expresa una observación (que recoge una opinión común). Debo esta observación a la exposición de Paul Hellmeier acerca del uso de las citas bíblicas en la Expositio, presentada en el primer congreso acerca de la Expositio, organizado por D. Calma y E. King, Dublin, 23-25 de octubre de 2019.

4. "Excellentia namque eius et praepollentia ad alios Platonicos evidenter apparet in hoc, quod ipsius Platonis theoremata ordinavit in praesenti libro et ordinata subtilissime declaravit". (Expositio, exp. tit. A p. 37, 25-27). Cfr. de Libera, 1994, p. 321.

5. En el prologus, el De malorum existentic de Proclo es citado como autoridad para referirse al punto de vista de la providencia voluntaria: "Ista sunt invisibilia Dei transitive accepta, de quibus in ista elementatione theologica subtilissime pertractatur, quantum pertinet ad providentiam naturalem. Sunt praeterea invisibilia Dei providentiae voluntariae, puta angeli, qui, ut dicit Proclus De malorum existentia 3 cap., sunt "genus interpretativum deorum continuum existens dis. Et intellectum novit deorum et elucidat divinam voluntatem; et est utique et ipsum divinum lumen ex lumine in abditis ente, quod et extra apparens et nihil aliud, quam bonum progressum et ex intus manentibus in uno prime elucescens. Oportet enim utique processum totorum continuum facere, consequenter autem aliud alii secundum naturam propter simile. Fonti quidem igitur bonorum consequenter multa bona; et numerus unitatum secretus manens in indicibili fontis, huic autem primus procedentium et procidentium numerus continuus, velut in prothyriis -id est pro foribus deorum ordinatus et pronuntians illorum silentium". Hoc ille. Expositio, prologus 5-6, vol. I, p. 13, 264-278. Agradezco esta advertencia a Evan King. Con todo, creo que también es posible que este texto de Proclo (que Bertoldo cita también al comentar la prop. 26, cfr. aquí mismo infra), venga a establecer el lugar que, "según el punto de vista del orden de la providencia natural", ocupa la naturaleza angélica.

6. Por razones paleográficas, en la Expositio la ípsilon de palabras griegas como autarkes aparece transliterada como N, e.g. antarkes. 
7. Véase la continuación del pasaje citado en el paréntesis anterior: "Verum prime productiva causa producit ea, quae sunt post se, immediate, scilicet ipsas bonitates in ordine universi, et quae sunt deinceps usque ad ultimum simpliciter inclusive. Dico autem immediate tam secundum providentiam naturalem, in qua bonitates obtinent primitatem, quam etiam secundum providentiam voluntariam, in qua Seraphim excedunt omnes angelicos spiritus "eo, quod ad ipsam thearchiam sine medio extenduntur omnia excedente virtute et ordine, ad castissimum et secundum omne ineffabile collocantur", ut dicit Dionysius 7 cap. Angelicae hierarchiae $H_{1} K$ L. Expositio 26H, vol. II, p. 158, 192-200. De acuerdo con este texto, según lo entiendo, la causa primera produce lo que viene inmediatamente después de ella, tanto en el caso del orden de la providencia natural (en el que lo inmediato son las unitates), cuanto en el caso del de la providencia voluntaria (en la que lo primero inmediato al Creador son los serafines).

8. "Si autem ad providentiam naturalem oculum considerationis coniecero, tunc angeli sunt continui dis, non iam prime Deo secundum intentionem auctoris 3 cap. De malorum existentia, ubi loquens de angelis sic dicit: "Genus autem interpretativum deorum continuum est dis et intellectum novit deorum et elucidat divinam voluntatem..." (Expositio $26 \mathrm{H}$, vol. II, p. 158, 201-205). Cito la traducción castellana del De malorum existentia de J. M. García Valverde (Madrid, Trotta, 2017), modificada. El mismo texto de Proclo es citado en el prologus. Cfr. supra, n. 13. único principado, son llamados príncipes porque, antes que cualquier otro (primum), reciben -del príncipe universal de todas las cosas- la dignidad del principado" (10A, I: $177,27-29)$.

Ahora bien, antarkia es también (2) la totalidad de los órdenes instaurados por estos principes partiales. Estos "príncipes" son los dioses de Proclo - en la traducción de Moerbeke, las unitates o bonitates. Así, la antarkia es un "orden divino por esencia proporcionalmente constituido a partir de las bondades o unidades perfectas por sí dentro de la intentio más absoluta gradualmente distribuidas entre sí y con relación a su monarca según una mayor o menor absolución" (10A, I: 177, 31-35).

Las unitates son principios subordinados inmediatos al Principio; residen intra absolutissimam intentionem. Esta intentio es, según otros pasajes de la Expositio, la intentio unitatis. Cada una instaura un orden, una antarkia, y hace las veces de monarca respecto del determinado orden por ella principiado. Por sobre estos dioses o príncipes está el prime Deus (cfr. 10A, I: 178, 61-64).

La antarkia -señala Bertoldo- difiere de la hierarchia. Si la primera es un orden divino que emana de Dios según la disposición de la providencia natural; la segunda es un orden divino emanado de Dios según la disposición de la providencia voluntaria. La antarkia es orden divino peressentiam. La hierarchia es orden divino constituido por seres que existen per participationem (cfr. 10A, vol. I, p. 178, 36-40). Desde el punto de vista del orden de la providencia natural, la hierarchia no es un orden inmediato al Principio, pues participa de Él sólo a través de los dioses o unitates. Pero desde el punto de vista de la providencia voluntaria, es inmediata al Creador. Ahora bien, en el orden jerárquico, los ángeles (y, entre estos, los serafines) ocupan el primer lugar.

Comentando la proposición 26 , Bertoldo retoma esta idea. La prime productiva causa hace inmediata, aunque ordenadamente (cfr. Ludueña, 2013a: 224-225), lo que viene después de ella (cfr. 26H, II: 158, 192-194), tanto según el orden de la providencia natural como según el de la providencia voluntaria. De acuerdo con este último, los órdenes angélicos ocupan la cumbre del universo creado. ${ }^{7}$ Ahora bien, esto no ocurre cuando nos concentramos en el orden de la providencia natural: "Si, en cambio, lanzo la mirada de la consideración a la providencia natural, entonces los ángeles ya no vienen a continuación del prime Deus, sino de los dioses" (26H, II: 158, 201-202).

Es decir, de acuerdo con el orden de la providencia natural - el de la Elementatio- las unitates o dioses obtinent primitatem (26H, II: 158,196$)$. Así lo advierte Proclo, en su De malorum existentia: "la estirpe de los intérpretes de los dioses viene a continuación de los dioses (continuum est dis) y conoce sus pensamientos y hace manifiesta la voluntad divina" (26H, II: 158, 201-205). ${ }^{8}$

Desde el punto de vista del orden natural, en el orden universal, los ángeles se ubican apenas por sobre el ser humano, y por debajo de las almas totales (i.e. de los astros) (cfr. 163E, VII: 28, 139-152). Esto se debe a la naturaleza de su actividad intelectual. En efecto, Bertoldo considera que los ángeles, como los hombres, poseen un cuerpo, sólo que un cuerpo más sutil o divino (cfr. 129A, V: 176, 194-19). Esto condiciona su autoconversión. Las unitates vuelven sobre sí mismas se totis et totaliter. Las hipóstasis que las siguen (infinitates, enter entia, vitae, intellectuales hypostases) vuelven sobre sí se totis pero no totaliter. El totaliter es dignidad exclusiva de la instancia que subsiste según una única intentio; el se totis es la (limitada) dignidad de todo aquello que no tiene relación con un cuerpo. Y justamente por esto, a los ángeles no les corresponde ni siquiera el se totis (65A, III: 202, 41-43): angeli, qui etiam non se totis convertuntur ad se totos (82C, IV: 121, 108-109). En otras palabras, los ángeles no son substancias simples (cfr. 171C, VII: 113, 128-134); y, así, en ellos, la conversión no se produce 
según la totalidad de su ser, sino sólo en cuanto a su parte superior (cfr. 15F, II: 22, $248-262) .^{9}$

Conocer este esquema permite advertir la función del pensamiento eriugeniano en la Expositio. Las causas primordiales de Eriúgena -hechas por el Padre en el Hijo (quae Pater in Filio fecit)-, ${ }^{10}$ son el equivalente cristiano de los dioses de la Elementatio.

La Expositio echa mano de una cantidad abrumadora de fuentes cristianas, paganas, árabes, hebreas. Y una de las fuentes que retornan con mayor insistencia en el comentario bertoldino son las fuentes eriugenianas. Bertoldo conoce el pensamiento de Eriúgena (sin saber que es de Eriúgena) a través de cuatro canales:

» directamente mediante la homilía de Eriúgena sobre el prólogo de Juan (que Bertoldo considera obra de Orígenes);

» indirectamente a través de tres fuentes:

» los escolios eriugenianos del Corpus dionisiano de Paris (que cree obra de Máximo);

» los extractos eriugenianos del Liber de causis primis et secundis (que, para Bertoldo, se llama De causa causarum y es obra de Alfarabi);

" la Clavis physicae de Honorio Augustodunense (para Bertoldo, escrita por un tal Teodoro).

Es decir que para Bertoldo, el pensamiento eriugeniano tiene cuatro nombres: Orígenes, Máximo, Alfarabi y Teodoro.

La manera en que Bertoldo introduce las citas de sus fuentes eriugenianas pone de manifiesto el papel que juega el pensamiento eriugeniano en ese diálogo constante entre el orden de la providencia voluntaria y el orden de la providencia natural. En este sentido, quiero señalar dos pasajes en donde Bertoldo cita a "Teodoro".

El comentario a la proposición 120 trata precisamente de la providencia. En especial, el segundo punto del propositum trata de duplici providentia (cfr. 120C, V: 93, 110-111). Bertoldo parte de un texto del De summo bono de Ulrico de Estrasburgo, que hace referencia a la distinción agustiniana entre los dos tipos de providencia (cfr. 120E, V: 100, 295-303). ${ }^{11}$ Ulrico cita incluso el texto correspondiente del De Genesi ad litteram (VIII, 9, 17), según el cual "gemina operatio providentiae reperitur, partim naturalis, partim voluntaria". Al primer acto de la providencia divina corresponde el ordo naturalis causarum (cfr. 120E, V: 100, 303). Bertoldo escribe que tal es el orden que in hoc volumine (es decir, la Expositio) exprimitur (120E, V: 100, 304). Y a continuación explica que, entre las causas naturales, las primordiales -a las que Proclo llama "dioses"superan al resto. Luego discute su naturaleza y emplea, para ello, un texto de la Clavis:

Según un primer acto de la providencia, se da un orden natural de causas» -aquel que halla expresión en este libro. Todas ellas son superadas por las mencionadas causas primordiales (a las que el autor llama 'dioses'). De estas causas primordiales, habla así Teodoro en la Clavis... (120E, V: 100, 303-305; la primera parte es todavía una paráfrasis del texto de Ulrico.)

Como se ve, la primera auctoritas a la que recurre Bertoldo para comenzar su estudio del orden de las causas naturales -el orden del que trata Proclo- es la Clavis physicae. El pensamiento eriugeniano es un ejemplo de pensamiento cristiano que, a diferencia de Dionisio, enfoca el universo desde el punto de vista del orden de la providencia natural. De hecho, cuando termina la cita de la Clavis, Bertoldo escribe:
9. Sobre este punto, cfr., también, Expositio 129F, vol. V, p. 181, 259-278.

10. Esta fórmula aparece ya en el prologus de la Expositio, cuando se cita uno de los famosos escolios del pseudo-Máximo presentes en el Corpus Dionysiacum de la Universidad de Paris. Cfr. Expositio, prologus 4, p. 10, 155-174; ex cod. Paris. Lat. 17341, 247rb / rb-va / ra-b (= Periphyseon II, 615D-617A, 3142-3188); apud Alb., Summa theol. I, 13, 55, 2, 1 (ed. Borgnet 559b-560a). También aparece en la Clavis physicae, por ejemplo, en Clavis phys. 82-83; ed. Lucentini: p. 59, 15-2, texto citado Expositio 97C, pp. 187-188, 89-101.

11. Se trata de una paráfrasis del De Summo bono Il, 5, 18, 9; ed. Beccarisi: pp. 145,258-146,266. 
12. En realidad, el texto no es de Dionisio sino de Tomás Galo: Si vero accipiantur invisibilia Dei transitive, quorum secundum Vercellensem super 11 cap. Dionysii $D e$ divinis nominibus "divina bonitas dicitur esse substantificatrix", scilicet "suorum invisibilium quasi radiorum superunitae bonitatis, ut sunt per se esse, per se vita, etc." -de quibus invisibilibus prosequitur Alfarabius in libello De causa causarum... Expositio, prologus. 4, vol. I, p. 9, 134-138. Cfr. Ludueña, 2013b, pp. 120-122.

13. La continuación del texto es: In naturali enim secundum Theodorum in Clave iste videtur ordo esse ut prima sint et suprema catholica elementa simplicissima et purissima, ex quibus per naturam compositionis determinantis naturam simplicitatis eorum primo constituantur corpora caelestia, deinde elementa sensibilia huius inferioris mundi, ex quibus deinceps componuntur mixta et elementata secundum suos gradus. Unde sic procedit incipiens a distinctione naturae creatae dicens: 'Totius conditae naturae trina divisio est. Omne enim, quod creatum est, aut omnino corpus est, ut terrena et aquatica, aut omnino spiritus, ut rationes rerum (scilicet primordiales causae), aut aliquid medium, ut quattuor elementa' Ibidem, p. 173, 16-24; Clavis phys. 179; ed. Lucentini: pp. 141,4-142,7; ex PP 695A-B. 14. Cfr. Vox spiritualis 9-10.

15. También aparece loannes Scotus, pero a través de un pasaje de la Summa theologiae de Alberto que Bertoldo insertó en el prólogo. Todo indica que Bertoldo no supo nunca que ese loannes era el verdadero autor de los textos de "Máximo", "Teodoro", "Orígenes" y "Alfarabi", que Bertoldo tanto admiraba. Cfr. King, 2019, pp. 401-411. hasta aquí Teodoro. En consecuencia, así como en la providencia natural Dios provee inmediatamente las causas primordiales, y a través de ellas y en ellas a absolutamente todas las causas, así también esto ocurre -a su modo- en la providencia voluntaria. Por lo cual, en el capítulo 13 de la Jerarquía angélica, Dionisio dice... (120E, V: 100, 321-325)

Tanto en uno como en otro orden, Dios opera a través de cooperadores subordinados. En un caso, las causas primordiales; en el otro, los ángeles. Dionisio ha expuesto todo lo referido a los ángeles. Pero, entre los cristianos, es "Teodoro" el que ha abordado el orden de causas naturales que las jerarquías dionisianas presuponen. (De hecho, en el prologus, a la hora de presentar a sus lectores a los dioses o unitates, Bertoldo parte de un texto de Dionisio para pasar enseguida a un texto de "Alfarabi", o sea, de Eriúgena). ${ }^{12}$

La exposición de la proposición 129 vuelve a recurrir a "Teodoro" para aclarar el punto de vista del orden natural, precisamente en el primer punto del suppositum, donde Bertoldo ofrece una clasificación corporum in generali (129A, V: 173, 11-12): "hay que saber que los cuerpos difieren según una doble providencia, una natural y una voluntaria. Y en el caso de la natural, de acuerdo con la Clavis de Teodoro, éste parece ser el orden..." $\left(129 \mathrm{~A}, \mathrm{~V}: 173,14^{-16}\right)^{13}$

Para Bertoldo, el pensamiento de la Clavis ofrece un punto de vista filosófico. En cuanto a sus otras fuentes eriugenianas, no dice explícitamente que también sean ejemplo de una reflexión sobre el orden natural del universo. Sin embargo, hay indicios bastantes claros de que eso es lo que piensa Bertoldo.

De la homilía, la única cita que figura en la Expositio compara la subsistencia causal de las cosas en el Verbo -en donde constituyen un unum- con fenómenos naturales como el modo en que en una única semilla subsiste una variedad de hierbas y frutos: "observa... -dice el texto de Eriúgena que elige citar Bertoldo- cómo la variedad de las plantas y de los frutos están, a un tiempo, contenidos en las semillas individuales..." (30D, II: 196, 200-210). ${ }^{14}$ Ahora bien, de acuerdo con el texto agustiniano del De Genesiad litteram en base al cual Teodorico de Freiberg diferencia entre los dos órdenes providenciales, que utiliza para explicar el sentido de la Elementatio theologica, la providencia natural opera "per occultam Dei administrationem, qua etiam lignis et herbis dat incrementum...". No parece injusto, pues, ubicar el acotado empleo que Bertoldo hace de la homilía de Eriúgena en el contexto de los desarrollos concernientes al orden de la providencia natural.

En cuanto al Liberde causis primis et secundis que Bertoldo atribuye a Alfarabi, hay un dato importante que nos permite conocer la categoría que el dominico le asignaba. Antes del prólogo de la Expositio Bertoldo colocó dos listas de autores. La de los doctores ecclesiae y la de los philosophifamosi a partir de cuyos libros y sentencias está confeccionada la Expositio (I: 3, 1-3 y 4, 1-3). En la segunda, junto a Platón, Aristóteles, Proclo y otros, figura precisamente Alfarabius De causa causarum -es decir, el Liber de causis primis et secundis-. En consecuencia, es muy posible que el opúsculo de "Alfarabi" represente para Bertoldo una reflexión sobre el orden de la providencia natural.

Resta la cuarta fuente eriugeniana de la Expositio: "Máximo". Aquí también vale la pena recurrir a las listas arriba mencionadas. En la de los doctores ecclesiae, figuran por supuesto Theodorus abbas Constantinopolitanus -i.e. la Clavis- y Origenes super Ioannem -i.e. la homilía eriugeniana-. ${ }^{15}$ Ahora bien, también figura Maximus commentator sancti Dionysii - para Bertoldo, autor de los escolios parisinos que hoy sabemos que son, en verdad, extractos del Periphyseon-. En cuanto a "Máximo" lo importante está en lo que lo define: es el commentator sancti Dionysii. Este, ciertamente, es el otro 
componente de la imagen del pensamiento eriugeniano propia de la Expositio, se trata de un comentario cristiano de Dionisio. Y es lícito entender que ese comentario, para Bertoldo, tiene un carácter filosófico. Es, por ejemplo, de uno de estos escolios de donde proviene una de las primeras precisiones acerca de los dioses o causas primordiales. ${ }^{16}$

Bertoldo no sabe que detrás de estas cuatro fuentes hay en última instancia un único autor, pero, si reunimos su visión de cada una de ellas, llegamos a la conclusión de que el eriugeniano es para Bertoldo un pensamiento que media entre Proclo y Dionisio. Es pensamiento platónico, es decir parte de la supersapientia nostra; es filosófico, o sea, puede dialogar con Proclo; y es cristiano y, en particular, un comentario de la doctrina dionisiana. Bertoldo encontró en el pensamiento eriugeniano una herramienta para mediar entre el politeísmo de Proclo y la postura dionisiana y mostrar, así, la armonía que se da entre lo que -para él- son dos versiones centrales del único pensamiento capital: el platónico. 


\section{Bibliografía}

" Bertholdus de Mosburch, (1984). Expositio super Elementationem theologicam Procli. Prologus. Propositiones 1-13, ed. M. R. Pagnoni-Sturlese \& L. Sturlese, Hamburgo (CPTMA 6,1).

» Bertholdus de Mosburch, (1986). Expositio super Elementationem theologicam Procli. Propositiones 14-34, ed. L. Sturlese, M. R. Pagnoni-Sturlese \& B. Mojsisch, Hamburgo. (CPTMA 6,2)

"Bertholdus de Mosburch, (2001). Expositio super Elementationem theologicam Procli. Propositiones 35-65, ed. A. Sannino, Hamburg. (CPTMA 6,3)

» Bertholdus de Mosburch, (2003). Expositio super Elementationem theologicam Procli. Propositiones 66-107, ed. I. Zavattero, Hamburgo. (CPTMA 6,4)

»Bertholdus de Mosburch, (2011). Expositio super Elementationem theologicam Procli. Propositiones 108-135, ed. F. Retucci, Hamburgo. (CPTMA 6,5)

»Bertholdus de Mosburch, (2007). Expositio super Elementationem theologicam Procli. Propositiones 136-159, ed. F. Retucci, Hamburgo. (CPTMA 6,6)

"Bertholdus de Mosburch, (2003). Expositio super Elementationem theologicam Procli. Propositiones 160-183, ed. U. R. Jeck \& I. Johanna Tautz, Hamburgo. (CPTMA 6,7)

》Bertoldo di Moosburg, (2014). Expositio super Elementationem theologicam Procli, Propositiones 184-211, ed. L. Sturlese \& A. Punzi, Hamburgo. (CPTMA 6,8)

» De Libera, A. (1989), Philosophie et théologie chez Albert le Grand et dans l'École dominicaine allemande. En A. Zimmermann (ed.), Die Kölner Universität im Mittelalter, (pp. 49-67). Berlin-New York.

» King, E. A. (2016), Supersapientia: A Study of Berthold von Moosburg. Tesis doctoral inédita. Cambridge.

» King, E. A. (2019), Eriugenism in Berthold of Moosburg's Expositio super Elementationem theologicam Procli, en D. Calma (ed.), Reading Proclus and the Book of Causes, (pp. 394-437), vol. 1, Leiden: Brill.

» Ludueña, E. (2013a), La recepción de Eriúgena en Bertoldo de Moosburg, Saarbrücken: Publicia.

» Ludueña, E. (2013b), Eriúgena en el siglo XIV: Su presencia en la Expositio de Bertoldo de Moosburg, Scintilla: Revista de Filosofía e Mistica Medieval 10/2, 99-154. 